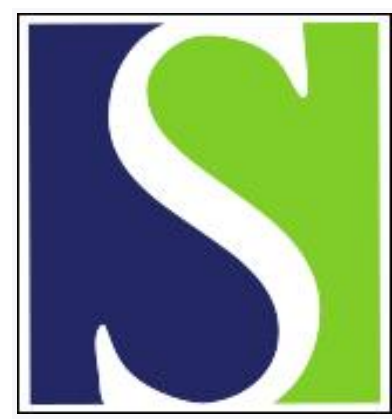

Scand J Work Environ Health 1987;13(1):37-46

https://doi.org/10.5271/sjweh.2083

Issue date: Feb 1987

Circulatory and thermal responses of men with different training status to prolonged physical work in dry and humid heat.

by Smolander J, IImarinen R, Korhonen O, Pyykko I

This article in PubMed: www.ncbi.nlm.nih.gov/pubmed/3576143

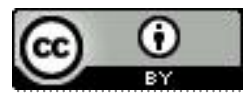




\title{
Circulatory and thermal responses of men with different training status to prolonged physical work in dry and humid heat
}

\author{
by Juhani Smolander, MSc, Raija IImarinen, PhD, OIli Korhonen, MD, IImari Pyykkö, MD¹
}

\begin{abstract}
SMOLANDER J, ILMARINEN R, KORHONEN O, PYYKKÖ I. Circulatory and thermal responses of men with different training status to prolonged physical work in dry and humid heat. Scand $J$ Work Environ Health 13 (1987) 37 - 46. Eight physically trained and eight untrained, unacclimated men walked on a treadmill at $30 \%$ of their maximum oxygen consumption up to $3.5 \mathrm{~h}$ in a thermoneutral $\left[20^{\circ} \mathrm{C} / 40\right.$ $\%$ relative humidity $(\mathrm{RH})]$, a warm humid $\left(30^{\circ} \mathrm{C} / 80 \% \mathrm{RH}\right)$, and a hot dry $\left(40^{\circ} \mathrm{C} / 20 \% \mathrm{RH}\right)$ environment while wearing industrial work clothing. Their oxygen consumption, rectal and skin temperatures, sweating, cardiac output, heart rate, stroke volume, and peripheral blood pressure were measured during the tests. Thirteen of the 32 heat stress tests were prematurely stopped due to high rectal temperature, high heart rate, subjective fatigue, or heat syncope. The physiological strain, as indicated by the rectal temperature and heart rate, was not significantly different between the warm humid and hot dry environments (wet bulb globe temperature $\sim 28^{\circ} \mathrm{C}$ ). The rectal temperature and heart rate responses of the physically trained and untrained subjects did not differ in any of the environments. In the heat, the heart rate was significantly higher than in the thermoneutral environment, but because of the markedly reduced stroke volume the average cardiac output was not different between the three environments. The impaired work performance in the heat seemed mainly to be related to the circulatory instability accompanying the increased cutaneous circulation.
\end{abstract}

Key terms: body temperature, central circulation, heat stress indices, hot dry environment, peripheral circulation, physical fitness, prolonged exercise, sweating, warm humid environment, work performance.

When people work for the first time in a hot environment, their work performance is often reduced, their heart rate and internal body temperatures may increase greatly, and they are prone to heat disorders such as heat syncope and heat exhaustion $(2,15,34)$. Depending on the severity of the environment and work load, man can adjust to a certain extent to heat stress by increased sweating and skin blood flow and thus attain a physiological steady state.

During physical exercise in the heat, the reduction of stroke volume has been shown to be an important mechanism limiting physical performance (29). In a hot environment at heavy work loads the lowered stroke volume seems to prevent any thermally induced rise in cardiac output $(5,18,29,32)$, and increments in skin blood flow occur through redistribution of the blood flow from visceral organs (27) and inactive muscles (14). Therefore, unacclimated subjects cannot reach a circulatory and thermal steady state during heavy work in the heat, and the work periods tend to be short.

Although the metabolic demands are usually relatively low ( $<30 \%$ of maximal oxygen consumption) in hot workplaces (16), the work periods last for several hours and work overalls are worn which can cause

\footnotetext{
I Institute of Occupational Health, Helsinki, Finland.
}

Reprint requests to: $\mathrm{Mr} \mathrm{J}$ Smolander, Institute of Occupational Health, Laajaniityntie 1, SF-01620 Vantaa, Finland. significant extra heat strain (11). Under these conditions, the increase in cardiac output may provide part of the increased skin blood flow needed to maintain thermal balance, as suggested by Brouha (3). Earlier observations $(4,18,21,30,34)$ indicate that, during light exercise in the heat, cardiac output may rise over control values. However, it is difficult to assess the significance of these findings in respect to work performance, because these studies employed either short-term exercise in an unusual body position (supine, semiupright) or a limited number of subjects (usually three or four).

The purpose of the present study was to investigate the circulatory and thermal responses of unacclimated men wearing ordinarily used industrial work clothing during $3.5 \mathrm{~h}$ of light treadmill work in a warm humid and a hot dry environment. Because the level of physical fitness has been shown to influence heat tolerance $(1,8,9)$, the measurements were made on two groups of men with a different physical training status.

\section{Subjects and methods}

\section{Subjects}

The subjects were eight physically trained and eight untrained healthy men, aged $28-37$ years (table 1 ). The subjects were not acclimated to heat, and none of them worked permanently in a hot workplace. Before the tests, oral and written information about the procedures was given to the subjects, and their informed consents were obtained. 
Table 1. Physical characteristics of the subjects.

\begin{tabular}{|c|c|c|c|c|c|c|c|c|c|c|c|c|}
\hline \multirow{3}{*}{ Group } & \multirow{2}{*}{\multicolumn{2}{|c|}{ Age (years) }} & \multirow{2}{*}{\multicolumn{2}{|c|}{ Height $(\mathrm{cm})$}} & \multirow{2}{*}{\multicolumn{2}{|c|}{ Weight $(\mathrm{kg})$}} & \multirow{2}{*}{\multicolumn{2}{|c|}{$\begin{array}{c}\text { Dubois body } \\
\text { surface area } \\
\left(\mathrm{m}^{2}\right)\end{array}$}} & \multicolumn{4}{|c|}{ Maximum oxygen consumption } \\
\hline & & & & & & & & & \multicolumn{2}{|c|}{$1 \cdot \min ^{-1}$} & \multicolumn{2}{|c|}{$\mathrm{ml} \cdot \mathrm{min}^{-1} \cdot \mathrm{kg}^{-1}$} \\
\hline & Mean & SD & Mean & SD & Mean & $\mathrm{SD}$ & Mean & SD & Mean & SD & Mean & SD \\
\hline $\begin{array}{l}\text { Trained }(\mathrm{N}=8) \\
\text { Untrained }(\mathrm{N}=8)\end{array}$ & $\begin{array}{l}31.8 \\
33.6\end{array}$ & $\begin{array}{l}2.5 \\
2.8\end{array}$ & $\begin{array}{l}175.3 \\
178.2\end{array}$ & $\begin{array}{l}6.3 \\
6.3\end{array}$ & $\begin{array}{l}72.2 \\
79.1\end{array}$ & $\begin{array}{l}6.3 \\
6.3\end{array}$ & $\begin{array}{l}1.87 \\
1.97\end{array}$ & $\begin{array}{l}0.12 \\
0.12\end{array}$ & $\begin{array}{l}4.22 \\
3.20\end{array}$ & $\begin{array}{l}0.52 \\
0.28\end{array}$ & $\begin{array}{l}59.1 \\
40.6\end{array}$ & $\begin{array}{l}5.2 \\
3.1\end{array}$ \\
\hline
\end{tabular}

Table 2. Environmental parameters used in the present study - Means and standard deviations for 16 tests.

\begin{tabular}{|c|c|c|c|c|c|c|}
\hline \multirow{3}{*}{ Parameter } & \multicolumn{6}{|c|}{ Environment } \\
\hline & \multicolumn{2}{|c|}{$\begin{array}{l}\text { Thermo- } \\
\text { neutral }\end{array}$} & \multicolumn{2}{|c|}{$\begin{array}{l}\text { Warm } \\
\text { humid }\end{array}$} & \multicolumn{2}{|c|}{ Hot dry } \\
\hline & Mean & SD & Mean & SD & Mean & $S D$ \\
\hline $\begin{array}{l}\text { Dry bulb } \\
\text { temperature } \\
\left({ }^{\circ} \mathrm{C}\right)\end{array}$ & 20.7 & 0.5 & 30.4 & 0.5 & 39.9 & 0.2 \\
\hline $\begin{array}{l}\text { Wet bulb } \\
\text { temperature } \\
\left({ }^{\circ} \mathrm{C}\right)\end{array}$ & 13.3 & 1.7 & 27.3 & 0.4 & 22.2 & 0.4 \\
\hline $\begin{array}{l}\text { Globe } \\
\text { temperature } \\
\left({ }^{\circ} \mathrm{C}\right)\end{array}$ & 20.6 & 0.4 & 30.6 & 0.6 & 39.9 & 0.2 \\
\hline WBGT ${ }^{\mathrm{a}}\left({ }^{\circ} \mathrm{C}\right)$ & 15.4 & 1.6 & 28.3 & 0.5 & 27.5 & 0.4 \\
\hline $\begin{array}{l}\text { Air velocity } \\
\left(\mathrm{m} \cdot \mathrm{s}^{-1}\right)\end{array}$ & $<0.3$ & . & $<0.3$ & . & $<0.3$ & . \\
\hline
\end{tabular}

a WBGT $=$ wet bulb globe temperature.

\section{Experimental procedures}

Before the experiments the subjects had a medical check-up including a clinical exercise test and routine examinations of blood and urine. Their maximum oxygen consumption ( $\left.\mathrm{V}_{2} \mathrm{max}\right)$ and anthropometric characteristics were then determined at a neutral room temperature.

The experimental part of the study consisted of three prolonged treadmill tests performed randomly in a climatic chamber, once in a thermoneutral $\left[20^{\circ} \mathrm{C} / 40 \%\right.$ relative humidity (RH)] once in a warm humid $\left(30^{\circ} \mathrm{C} / 80 \% \mathrm{RH}\right)$, and once in a hot dry $\left(40^{\circ} \mathrm{C} / 20 \%\right.$ $\mathrm{RH}$ ) environment (table 2). In addition, these three tests were preceded by a similar training walk in the thermoneutral climate in order to accustom the subjects to the experimental procedures. The two hot environments were chosen to give the same heat stress index value in terms of wet bulb globe temperature (WBGT), and they were within the range of thermal work conditions found in hot workplaces in Finland (22). All the tests took place in the morning, with an interval of at least one week between the tests to avoid acclimation effects. During the tests the subjects wore short-sleeved and short-legged cotton underwear, cotton work overalls, socks, and sneakers. The thermal insulation value of the clothing, measured from a thermal mannequin, was $0.109 \mathrm{~K} \cdot \mathrm{m}^{2} \cdot \mathrm{W}^{-1}(0.7 \mathrm{clo})$.

During the $48 \mathrm{~h}$ preceding the actual tests the subjects were asked to maintain their normal diet, to avoid any excessive physical exertion, and not to use any medication or alcoholic beverages. They reported to the laboratory at around 0645 after having a light breakfast without coffee or tea. They were also asked not to smoke in the morning before the tests. The thermistors and electrodes were attached, and the subjects had a 30 -min rest period in a lying position in a thermoneutral environment. The treadmill tests consisted of seven 30 -min work periods at $30 \% \mathrm{VO}_{2}$ max interrupted by 5 -min pauses for weighing. During the tests, flavored, lukewarm water was offered ad libitum, and drinking was encouraged. After exercising, the subjects rested for $30 \mathrm{~min}$ as they had done before the tests.

The tests were discontinued if the rectal temperature or heart rate increased constantly without achieving steady state. The fixed end points were $38.6^{\circ} \mathrm{C}$ for rectal temperature and 160 beats $\cdot \mathrm{min}^{-1}$ for heart rate. Other termination criteria were subjective fatigue and syncopal symptoms.

\section{Measurements}

The $\dot{\mathrm{V}}_{2}$ max of the subjects was directly measured on a treadmill by a method modified from that of $\mathrm{Oja}$ et al (24). The expired air was directed through lowresistance tubing (modified Koegel Y-valve) to 150-1 neoprene bags. The ventilation volume was measured with a calibrated dry gas meter. Gas analyses were performed with an infrared carbon dioxide $\left(\mathrm{CO}_{2}\right)$ analyzer (Morgan 80ld, PK Morgan Ltd, England) and a paramagnetic oxygen analyzer (Morgan 500d). Before each test the analyzers were calibrated with standard gas mixtures.

During the experiments in different environments the pulmonary ventilation and oxygen consumption were measured for every second work period by the Morgan Exercise Test System (PK Morgan, England), which, in addition to the aforementioned analyzers, includes a microprocessor and ventilometer. During the tests the electrocardiogram was continuously monitored (OLLI 332, Kone, Finland).

Cardiac output during each 30-min exercise period was estimated two to four times by a simplified $\mathrm{CO}_{2}$-rebreathing technique $(6,18,23)$ utilizing a rapidly responding infrared $\mathrm{CO}_{2}$ analyzer (Datex $\mathrm{CD}$ 101, Datex, Finland) and a portable chart recorder (YEW 3057-21, Yokogawa Electric Works, Japan). During the first training walk the subjects became accustomed to the rebreathing protocol. 
The analysis of the obtained curve and the calculations were done with a digitizer (HP9111A Graphics Tablet, Hewlett-Packard, United States) connected to a desk-top computer (HP85). A standard $\mathrm{CO}_{2}$ dissociation curve for oxygenated blood was used to estimate $\mathrm{CO}_{2}$ concentrations in the arterial and mixed venous blood $(17,26)$. For all the accepted $\mathrm{CO}_{2}$-rebreathing curves, the correlation coefficients in the estimation of $\mathrm{CO}_{2}$ pressure in the mixed venous blood were over 0.90 . Heart rate at the beginning of the rebreathing was used to estimate the stroke volume. The cardiac output determinations within one 30 -min work period were averaged for the analysis. For one subject working in the warm humid environment, the $\mathrm{CO}_{2}$ rebreathing was not done for technical reasons.

During the last $5 \mathrm{~min}$ of each work period the digital systolic blood pressure was measured by straingauge plethysmography (Medimatic SP2, Medimatic, Denmark) from the left middle finger as described previously (7). For the measurement the forearm was placed on a padded support at heart level. The digital systolic blood pressure of the physically trained men was also measured while the men stood beside the treadmill. However, this procedure appeared to provoke syncopal symptoms (see the Results section), and it was not used with the untrained men.

Internal body temperature was measured during the tests with a rectal probe (YSI 401, Yellow Springs Instruments, United States) inserted $10 \mathrm{~cm}$ beyond the anal sphincter. Skin temperatures were measured with thermistors (YSI 427) attached at nine sites with surgical tape (Scanpor, Norgesplaster, Norway). The mean skin temperature was calculated as the areaweighted average of the nine skin temperatures (11). Body temperatures and heart rate were recorded every minute with a desk-top computer (HP85) via an analogue digital converter (HP2397A).

The total body evaporation rate was determined after each 30 -min period from changes in clothed body weights, and the total body sweat rate was estimated by adding the weight gain in clothes to the total amount of evaporation, adjustment being made for water intake and urination. The weight gain in clothes was measured at the end of each test before the recovery period. In our tests, the amount of dripping sweat (from hands, legs, and face), which is difficult to quantify, was not accounted for, and it is thus included in the obtained evaporation rates. A differential balance with an accuracy of $\pm 10 \mathrm{~g}$ (Schember, Austria) was used.

Total skin blood flow was estimated from calculations of the whole-body thermal conductance (21).

\section{Statistical methods}

The differences in the circulatory and thermal parameters were tested between the three environmental conditions and between the two groups by the two-way analysis of variance with repeated measures on ambient temperature (33). If a significant main effect was found between the environments, the Newman-Keuls procedure was performed to locate the significant differences between the means. In the case of significant interactions a modified F-test was used to test the group differences for each environmental condition. Because of the dropouts during the tests (see the Results section), the analysis of variance was performed over values obtained for the steadily changing variables (heart rate, stroke volume, digital systolic blood pressure, mean skin temperature, rectal temperature) during the fourth work period or over the mean values of the steady variables (oxygen consumption, thermal conductance, evaporation rate, cardiac output) and the derived variables (weight loss, sweat rate) over the entire test. The linear regression technique was used to correlate the thermoregulatory responses with changes in cardiac output. The differences were considered statistically significant when $\mathrm{p}<0.05$.

\section{Results}

The subjects had no difficulties in accomplishing the exercise task in the thermoneutral environment, as indicated by the stable heart rate and rectal temperature. In both of the hot environments, however, a physiological steady state was achieved only in nine of the 32 tests. A total of 13 heat stress tests were prematurely discontinued (table 3). Three syncope episodes took place in the warm humid environment, and they all occurred in the trained group as the subject stood still beside the treadmill for a blood pressure measurement. (See the Subjects and Methods section.) Eight of the 13 premature cessations took place in the trained group.

\section{Metabolic and thermal responses}

During the prolonged tests in the thermoneutral environment the physically untrained subjects had a lower absolute level of oxygen consumption in comparison to that of the trained men (table 4), but the relative work levels ( $\left.\% \mathrm{VO}_{2} \mathrm{max}\right)$ of the groups were equal, the mean and standard error (SE) of the mean being 30.7 and $1.0 \%$, respectively, for the untrained and 31.4 and $1.2 \%$, respectively, for the trained groups.

Table 3. Distribution of the tests discontinued in the warm humid and hot dry environments according to the criterion for discontinuation.

\begin{tabular}{lcc}
\hline Criterion & \multicolumn{2}{c}{ Environment } \\
\cline { 2 - 3 } & $\begin{array}{c}\text { Warm } \\
\text { humid }\end{array}$ & $\begin{array}{l}\text { Hot } \\
\text { dry }\end{array}$ \\
\hline Rectal temperature $\geq 38.6^{\circ} \mathrm{C}$ & 4 & 1 \\
Heart rate $\geq 160$ beats $\cdot \mathrm{min}^{-1}$ & - & 1 \\
Subjective fatigue & 1 & 2 \\
Syncopal symptoms & 3 & 1 \\
\hline Total & 8 & 5 \\
\hline
\end{tabular}


Table 4. Metabolic and thermal responses of the physically trained $(N=8)$ and untrained $(N=8)$ groups to prolonged light exercise in the thermoneutral, warm humid, and hot dry environments and the results from the analysis of variance. The means and standard errors of the means are presented for the fourth work period (mean rectal and skin temperature) or for all the work periods averaged over the entire test (thermal conductance, sweat rate, evaporation rate, weight loss, oxygen consumption).

\begin{tabular}{|c|c|c|c|c|c|c|c|c|}
\hline \multirow{4}{*}{ Variable } & \multicolumn{6}{|c|}{ Environment } & & \\
\hline & \multirow{2}{*}{\multicolumn{2}{|c|}{$\begin{array}{l}\text { Thermoneutral } \\
\text { (A) }\end{array}$}} & \multirow{2}{*}{\multicolumn{2}{|c|}{$\begin{array}{l}\text { Warm humid } \\
\text { (B) }\end{array}$}} & \multirow{2}{*}{\multicolumn{2}{|c|}{$\begin{array}{l}\text { Hot dry } \\
\text { (C) }\end{array}$}} & \multicolumn{2}{|c|}{ Main effects } \\
\hline & & & & & & & Environment & Training \\
\hline & Mean & SE & Mean & SE & Mean & SE & & \\
\hline \multicolumn{9}{|c|}{ Rectal temperature $\left({ }^{\circ} \mathrm{C}\right)$} \\
\hline $\begin{array}{l}\text { Trained group } \\
\text { Untrained group }\end{array}$ & $\begin{array}{l}37.7 \\
37.6\end{array}$ & $\begin{array}{l}0.2 \\
0.4\end{array}$ & $\begin{array}{l}38.3 \\
38.0\end{array}$ & $\begin{array}{l}0.2 \\
0.4\end{array}$ & $\begin{array}{l}38.1 \\
38.0\end{array}$ & $\begin{array}{l}0.3 \\
0.3\end{array}$ & $A<B, C$ & NS \\
\hline \multicolumn{9}{|c|}{ Mean skin temperature $\left({ }^{\circ} \mathrm{C}\right)$} \\
\hline $\begin{array}{l}\text { Trained group } \\
\text { Untrained group }\end{array}$ & $\begin{array}{l}31.3 \\
31.5\end{array}$ & $\begin{array}{l}0.2 \\
0.5\end{array}$ & $\begin{array}{l}36.2 \\
35.0\end{array}$ & $\begin{array}{l}0.2^{++} \\
0.5\end{array}$ & $\begin{array}{l}36.0 \\
35.3\end{array}$ & $\begin{array}{l}0.2^{+} \\
0.8^{+}\end{array}$ & $A<B, C$ & * \\
\hline \multicolumn{7}{|c|}{ Thermal conductance $\left(\mathrm{W} \cdot \mathrm{m}^{-2} \cdot{ }^{\circ} \mathrm{C}^{-1}\right)$} & , & \\
\hline $\begin{array}{l}\text { Trained group } \\
\text { Untrained group }\end{array}$ & $\begin{array}{l}34 \\
24\end{array}$ & $\begin{array}{l}5 \\
1\end{array}$ & $\begin{array}{r}101 \\
54\end{array}$ & $\begin{array}{l}9^{++} \\
5\end{array}$ & $\begin{array}{r}106 \\
59\end{array}$ & $\begin{array}{l}9^{++} \\
6\end{array}$ & $A \stackrel{* *}{A}<, C$ & ** \\
\hline \multicolumn{9}{|c|}{ Sweat rate $\left(\mathrm{g} \cdot \mathrm{m}^{-2} \cdot \mathrm{h}^{-1}\right)$} \\
\hline $\begin{array}{l}\text { Trained group } \\
\text { Untrained group }\end{array}$ & $\begin{array}{l}169 \\
107\end{array}$ & $\begin{array}{l}5 \\
10\end{array}$ & $\begin{array}{l}475 \\
270\end{array}$ & $\begin{array}{l}35^{++} \\
30\end{array}$ & $\begin{array}{l}468 \\
340\end{array}$ & $\begin{array}{l}23^{++} \\
25\end{array}$ & $A<B, C$ & ** \\
\hline \multicolumn{9}{|c|}{ Evaporation rate $\left(\mathrm{g} \cdot \mathrm{m}^{-2} \cdot \mathrm{h}^{-1}\right)$} \\
\hline $\begin{array}{l}\text { Trained group } \\
\text { Untrained group }\end{array}$ & $\begin{array}{l}163 \\
102\end{array}$ & $\begin{array}{l}5 \\
10\end{array}$ & $\begin{array}{l}231 \\
178\end{array}$ & $\begin{array}{l}9 \\
10\end{array}$ & $\begin{array}{l}390 \\
300\end{array}$ & $\begin{array}{l}14 \\
14\end{array}$ & $A<B<C$ & ** \\
\hline \multicolumn{9}{|l|}{ Weight loss $(\%)$} \\
\hline $\begin{array}{l}\text { Trained group } \\
\text { Untrained group }\end{array}$ & $\begin{array}{l}0.7 \\
0.6\end{array}$ & $\begin{array}{l}0.1 \\
0.1\end{array}$ & $\begin{array}{l}1.1 \\
1.1\end{array}$ & $\begin{array}{l}0.1 \\
0.1\end{array}$ & $\begin{array}{l}1.7 \\
0.9\end{array}$ & $\begin{array}{l}0.3^{++} \\
0.1\end{array}$ & $A<B, C$ & NS \\
\hline \multicolumn{9}{|c|}{ Oxygen consumption $\left(I \cdot \mathrm{min}^{-1}\right)$} \\
\hline $\begin{array}{l}\text { Trained group } \\
\text { Untrained group }\end{array}$ & $\begin{array}{l}1.31 \\
0.98\end{array}$ & $\begin{array}{l}0.03 \\
0.05\end{array}$ & $\begin{array}{l}1.34 \\
1.04\end{array}$ & $\begin{array}{l}0.04 \\
0.05\end{array}$ & $\begin{array}{l}1.30 \\
0.98\end{array}$ & $\begin{array}{l}0.04 \\
0.05\end{array}$ & $A<B * C$ & ** \\
\hline
\end{tabular}

$+p<0.05,+p<0.01$, for interaction effects between the environment and training

* $p<0.05,{ }^{* *} p<0.01$ for the main effects of environment or training (NS = not statistically significant).

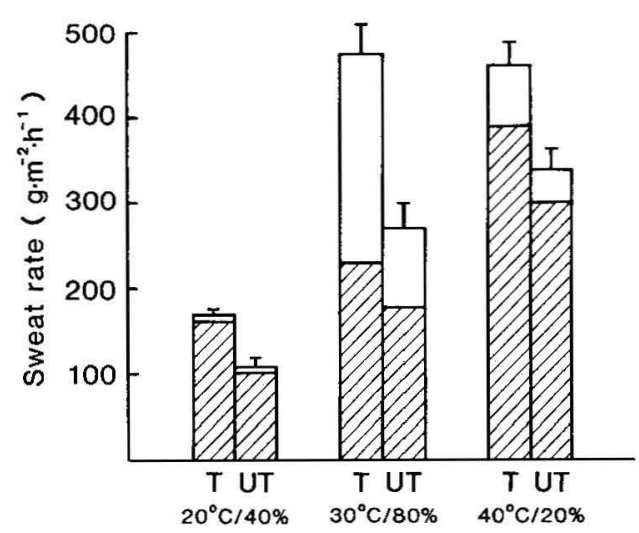

Figure 1. Sweat rate of the physically trained $(\mathrm{T})$ and untrained (UT) subjects in the thermoneutral $\left(20^{\circ} \mathrm{C} / 40 \%\right)$, warm humid $\left(30^{\circ} \mathrm{C} / 80 \%\right)$ and hot dry $\left(40^{\circ} \mathrm{C} / 20 \%\right)$ environments. The values are given as the means and standard errors of the means. The hatched areas indicate the corresponding evaporation rates, and the ambient temperature and the percentage of humidity are shown under the columns.

In both groups, the mean oxygen consumption was slightly higher $(p<0.01)$ in the warm humid environment than in the thermoneutral and hot dry environments.

Before the subjects walked in the thermoneutral, warm humid, and hot dry environments, their rectal temperatures did not differ between the groups, the average being 36.7 (SE 0.06$)^{\circ} \mathrm{C}, 36.7(\mathrm{SE} 0.06)^{\circ} \mathrm{C}$, and 36.8 (SE 0.05$)^{\circ} \mathrm{C}$, respectively, for the three environments. During the second work period in the thermoneutral environment, the rectal temperatures steadied to a similar level in both groups (table 4). In the heat, the rectal temperature increased constantly in most of the subjects, and five tests were discontinued because the subject's rectal temperature reached $\geq 38.6^{\circ} \mathrm{C}$ (table 3). No significant group differences were found for the rectal temperatures, although they tended to be slightly higher in the trained group in the heat. At the end of the 30-min recovery period, the rectal temperatures were higher $(p<0.01)$ after work in the warm humid and hot dry environments, but the differences between the groups were not significant.

The mean skin temperatures were higher $(p<0.01)$ in the warm humid and hot dry environments, and those of the physically trained subjects were about $1.0^{\circ} \mathrm{C}$ higher than those of the untrained men $(\mathrm{p}<0.01$ in the warm humid environment, $p<0.05$ in the hot dry environment). Consequently, the mean whole-body thermal conductance in the heat was $47 \mathrm{~W} \cdot \mathrm{m}^{-2} \cdot{ }^{\circ} \mathrm{C}^{-1}$ higher $(\mathrm{p}<0.01)$ in the physically trained than in the untrained men (table 4).

The physically trained subjects had higher $(p<0.01)$ evaporation and sweat rates as compared to the untrained subjects (table 4 and figure 1). The sweat rates did not differ in the warm humid and hot dry envi- 
ronments, but the evaporation rate was significantly lower in the warm humid environment, in which 49 $\%$ of the sweat produced by the physically trained subjects evaporated as compared to $66 \%$ of the sweat of the untrained subjects $(p<0.01)$. The deficits in nude body weight after work in the two hot environments were higher $(p<0.01)$ than the corresponding values in the thermoneutral environment.

\section{Cardiovascular responses}

Altogether 788 acceptable $\mathrm{CO}_{2}$-rebreathing curves (17 per test) were analyzed for cardiac output estimation. The consecutive determinations of cardiac output varied little in the tests in the thermoneutral environment, the coefficient of variation (standard deviation/mean $\times 100$ ) averaging $7.2 \pm 0.7 \%$.

Due to the higher absolute work loads, the physically trained subjects exhibited a higher $(\dot{p}<0.05)$ level of cardiac output than the untrained subjects (table 5 and figure 2), but there was no significant difference in cardiac output between the three environmental conditions. In the warm humid and hot dry environments, however, the individual variation in the cardiac output responses was higher than in the thermoneutral environment. Elevated, unchanged or lowered cardiac output was found in different tests (figure 3 ). In spite of the individual variability, the time courses of the cardiac output responses were rather steady throughout each test. The changes in the cardiac output values in the warm humid and hot dry environments relative to the corresponding values under the thermoneutral conditions correlated significantly $(r=0.51$, $\mathrm{p}<0.01, \mathrm{~N}=31$ ) with the changes in thermal conductance but not with the changes in the evaporation $(r=-0.11, \mathrm{NS})$ or sweat rate $(r=-0.05, \mathrm{NS})$.

As shown in figure 2, the mean stroke volume de- clined similarly in the warm humid and hot dry environments $(p<0.01)$ as compared to mean stroke volume under the thermoneutral conditions. Most of the reduction occurred during the first $2 \mathrm{~h}$ of exercise, after which the stroke volume reached a relatively steady level of about $100 \mathrm{ml}$ in the physically trained and 90 $\mathrm{ml}$ in the untrained subjects. In the thermoneutral environment, the stroke volumes were constant, the mean level varying from 131 to $138 \mathrm{ml}$ for the trained men and from 105 to $118 \mathrm{ml}$ for the untrained men. In all the environments the stroke volumes of the physically trained subjects were significantly $(p<0.01)$ higher.

Because the mean level of cardiac output was not different in the three environments, the reductions in stroke volume in the heat were compensated by elevated heart rates $(\mathrm{p}<0.01)$. As both groups exercised at similar relative work loads, the heart rates were nearly on the same level in the thermoneutral environment (figure 2). In the heat the heart rate response did not significantly differ between the groups.

At the end of the rest period before and after the tests the mean heart rate of the physically trained men was lower $(\mathrm{p}<0.01)$. Thirty minutes after the work in the warm humid and hot dry environments was completed, the mean heart rate was 15 beats $\cdot \mathrm{min}^{-1}$ higher than $30 \mathrm{~min}$ after the test in the thermoneutral environment. Heart rate recovery was similar in both groups.

The mean digital systolic blood pressure remained stable during the $3.5 \mathrm{~h}$ of work in the thermoneutral environment (table 5). In the warm humid and hot dry environments it decreased during the first hour, whereafter it remained steady.

Figure 4 illustrates the circulatory responses of two subjects. One had an elevated cardiac output in the warm humid and hot dry environments, his heart rate increased continuously, and his stroke volume was

Table 5. Circulatory responses of the trained $(\mathrm{N}=8)$ and untrained $(\mathrm{N}=8)$ subjects to prolonged light exercise in the thermoneutral, warm humid, and hot dry environments and the results from the analysis of variance. The means and the standard error of the means are presented for the fourth work period (stroke volume, heart rate, digital systolic blood pressure) or for all the work periods averaged over the entire test (cardiac output).

\begin{tabular}{|c|c|c|c|c|c|c|c|c|}
\hline \multirow{4}{*}{ Variable } & \multicolumn{6}{|c|}{ Environment } & & \\
\hline & \multirow{2}{*}{\multicolumn{2}{|c|}{$\begin{array}{l}\text { Thermoneutral } \\
\text { (A) }\end{array}$}} & \multirow{2}{*}{\multicolumn{2}{|c|}{$\begin{array}{l}\text { Warm humid } \\
\text { (B) }\end{array}$}} & \multirow{2}{*}{\multicolumn{2}{|c|}{$\begin{array}{l}\text { Hot dry } \\
\text { (C) }\end{array}$}} & \multicolumn{2}{|c|}{ Main effects } \\
\hline & & & & & & & \multirow[t]{2}{*}{ Environment } & \multirow[t]{2}{*}{ Training } \\
\hline & Mean & SE & Mean & SE & Mean & $\mathrm{SE}$ & & \\
\hline \multicolumn{9}{|l|}{ Stroke volume (ml) } \\
\hline $\begin{array}{l}\text { Trained group } \\
\text { Untrained group }\end{array}$ & $\begin{array}{l}135 \\
107\end{array}$ & $\begin{array}{l}7 \\
7\end{array}$ & $\begin{array}{r}100 \\
91\end{array}$ & $\begin{array}{l}6 \\
6\end{array}$ & $\begin{array}{r}105 \\
84\end{array}$ & $\begin{array}{l}6 \\
5\end{array}$ & $A<B, C$ & ** \\
\hline \multicolumn{9}{|c|}{ Heart rate (beats $\cdot \min ^{-1}$ ) } \\
\hline $\begin{array}{l}\text { Trained group } \\
\text { Untrained group }\end{array}$ & $\begin{array}{l}89 \\
99\end{array}$ & $\begin{array}{l}3 \\
4\end{array}$ & $\begin{array}{l}134 \\
123\end{array}$ & $\begin{array}{l}6 \\
7\end{array}$ & $\begin{array}{l}121 \\
121\end{array}$ & $\begin{array}{l}5 \\
5\end{array}$ & $\begin{array}{c}* * \\
A<B, C\end{array}$ & NS \\
\hline \multicolumn{9}{|c|}{$\begin{array}{l}\text { Digital systolic blood } \\
\text { pressure }\left(\mathrm{mmHg}^{\mathrm{a}}\right)\end{array}$} \\
\hline $\begin{array}{l}\text { Trained group } \\
\text { Untrained group }\end{array}$ & $\begin{array}{l}117 \\
111\end{array}$ & $\begin{array}{l}7 \\
6\end{array}$ & $\begin{array}{l}108 \\
104\end{array}$ & $\begin{array}{l}8 \\
4\end{array}$ & $\begin{array}{l}112 \\
105\end{array}$ & $\begin{array}{l}8 \\
2\end{array}$ & $A<B, C$ & NS \\
\hline \multicolumn{9}{|c|}{ Cardiac output $\left(1 \cdot \mathrm{min}^{-1}\right)$} \\
\hline $\begin{array}{l}\text { Trained group } \\
\text { Untrained group }\end{array}$ & $\begin{array}{l}12.1 \\
11.0\end{array}$ & $\begin{array}{l}0.4 \\
0.5\end{array}$ & $\begin{array}{l}12.9 \\
11.2\end{array}$ & $\begin{array}{l}0.4 \\
0.6\end{array}$ & $\begin{array}{l}12.9 \\
10.5\end{array}$ & $\begin{array}{l}0.7 \\
0.7\end{array}$ & NS & * \\
\hline
\end{tabular}

$1 \mathrm{mmHg} \sim 133.3 \mathrm{~Pa}$

${ }^{\star} p<0.05,{ }^{\star \star} p<0.01$ for the main effects of environment or training (NS = not statistically significant). 
(a) Trained
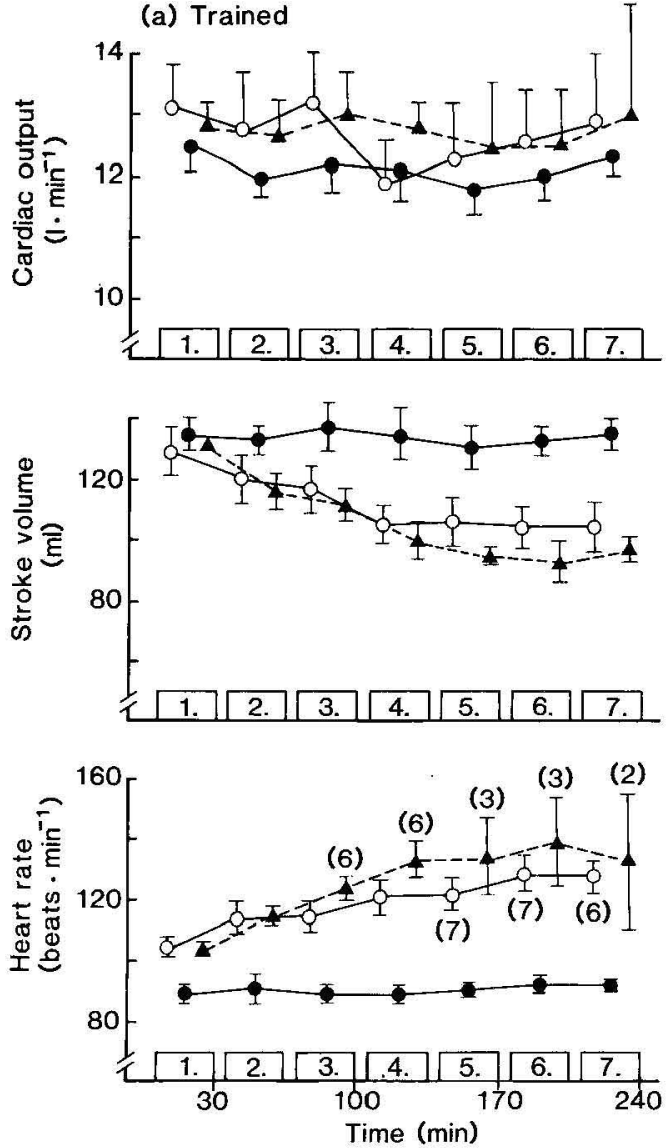

(b) Untrained
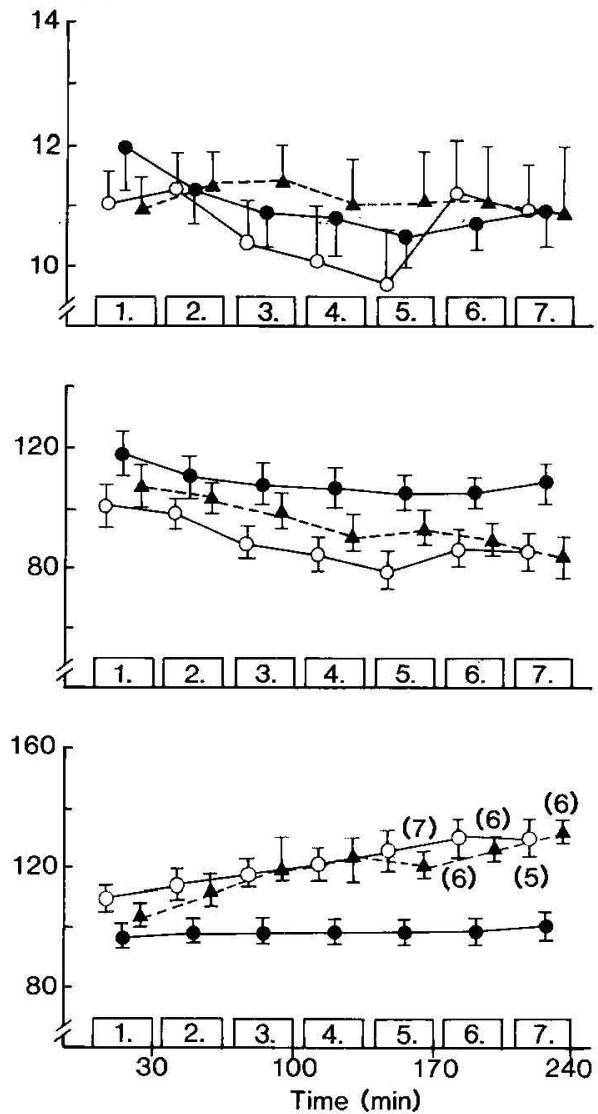

Figure 2. Cardiac output, stroke volume, and heart rate response of the physically trained (a) and untrained (b) subjects to prolonged exercise in a thermoneutral $(\bullet)$, warm humid $(\mathbf{A})$, and hot dry $(0)$ environment. The values are given as the means and standard errors of the means. Due to dropouts from the heat stress tests the number of subjects decreased with time as indicated in parentheses in the heart rate figure.

(a)

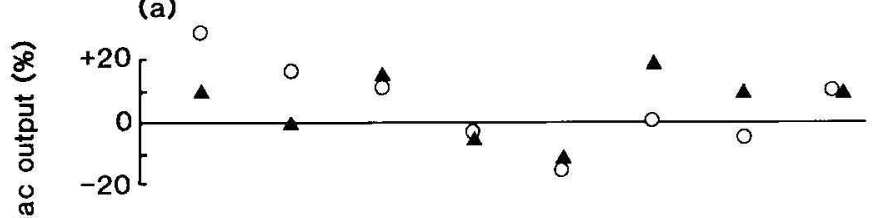

(b)

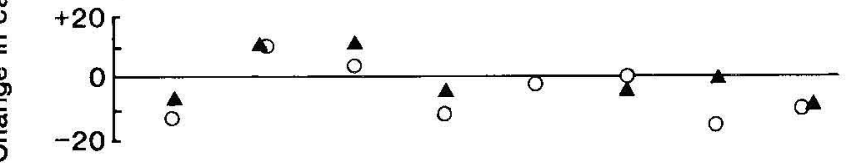

Figure 3. The individual changes in the cardiac output of the physically trained (a) and untrained (b) subjects in the warm humid $(\mathbf{A})$ and hot dry (O) environments relative to the cardiac output in the thermoneutral environment (zero level).

markedly reduced. The other subject reached a steadystate level in both heat stress tests and had a slightly lowered cardiac output. The digital systolic blood pressure of both subjects remained steady throughout the experiments, although it varied markedly with time.

\section{Discussion}

During the prolonged treadmill work requiring $30 \%$ $\mathrm{VO}_{2} \max$ in the warm humid and hot dry environ- ments, as compared to similar performance in the thermoneutral environment, our subjects exhibited the typical signs of unacclimated persons when initially exposed to work in a hot environment $(2,5,15,34)$, ie, elevated heart rate and rectal temperature and reduced physical performance, as evidenced by the $41 \%$ rate of premature test interruptions. Only three subjects were able to achieve a circulatory and thermal steady state in both of the hot environments. It is therefore obvious that, in workplaces with thermal work con- 
(a)
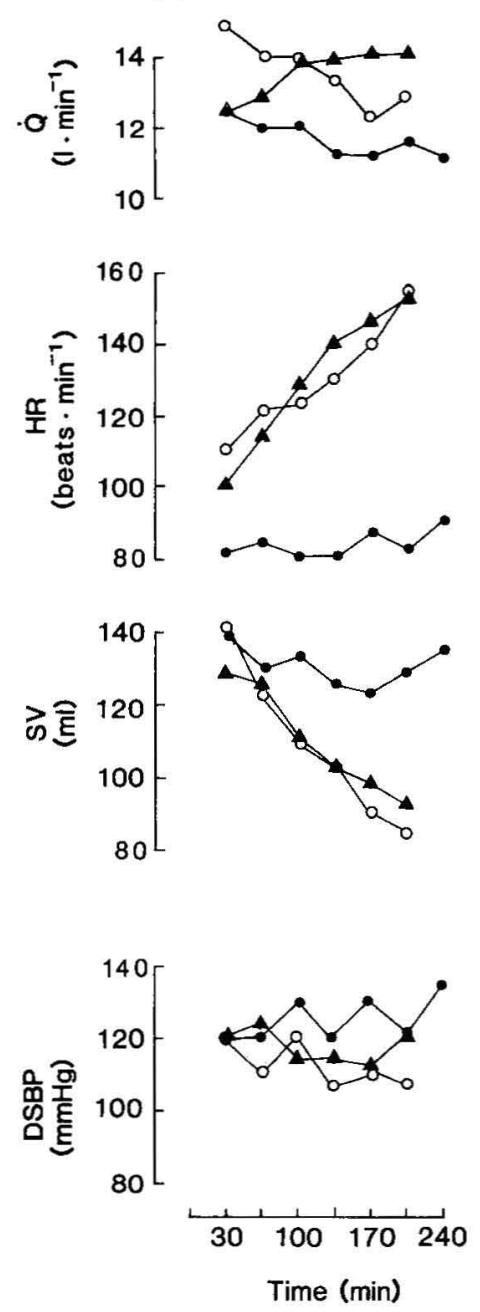

(b)
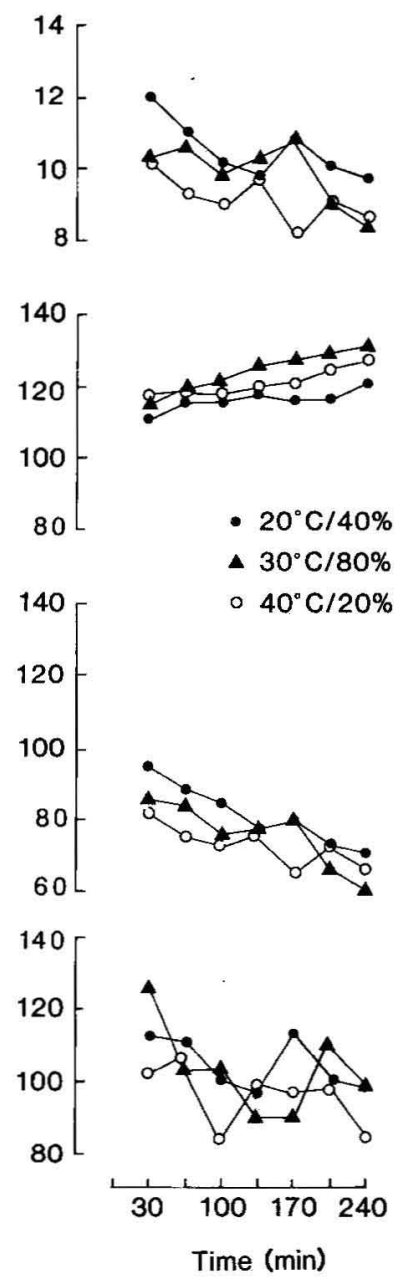

Figure 4. The circulatory response of one trained (a) and one untrained (b) subject to prolonged exercise in a thermoneutral, a warm humid, and a hot dry environment. The ambient temperature and the percentage of humidity are shown with the symbols. After the sixth exercise period both of the physically trained subject's heat stress tests were stopped, once due to exhaustion (hot dry) and once due to his rectal temperature reaching $38.6^{\circ} \mathrm{C}$. $Q=$ cardiac output, $\mathrm{HR}=$ heart rate, $\mathrm{SV}=$ stroke volume, DSBP = digital systolic blood pressure) ditions similar to our test environments (WBGT value of about $28^{\circ} \mathrm{C}$ as the heat stress index), it is necessary to reduce the heat stress, as indicated also by the reference values in the international heat stress standard (12). However, in spite of the equivalent WBGT values, the warm humid environment seemed to be somewhat more severe, as indicated by the slightly higher heart rates and higher incidence of heat syncope, than the hot dry environment.

With the use of the recently proposed (13) analytical heat stress index ("required sweat rate") the warm humid environment was also predicted to exert the highest thermal strain, especially in the physically trained group working at a higher metabolic rate. According to the model the duration-limited exposure times (danger level) predicted for humid heat were 1 h 8 min and 3 h 46 min for the physically trained and untrained men, respectively. The corresponding figures for the dry heat were $2 \mathrm{~h} 53 \mathrm{~min}$ and $6 \mathrm{~h} 18 \mathrm{~min}$. The latter values are in contrast to our result of no significant difference in physiological strain between the two groups. The higher sweat rates observed for the trained men in our study, as compared to the maximum criterion value of $650 \mathrm{~g} \cdot \mathrm{h}^{-1}\left(250 \mathrm{~W} \cdot \mathrm{m}^{-2}\right)$ used in the model, probably explains some part of this discrepancy. Actually, the predicted limit for exposure duration for an acclimated person in the hot dry environment would be $7 \mathrm{~h} 7 \mathrm{~min}$. Therefore it is possible that the higher sweat rates coupled with aerobic physical fitness $(1,8,9)$ should be accounted for in the criteria used for unacclimated persons in calculations of allowable work times.

\section{Circulatory adjustments}

The present study employed a simple, noninvasive $\mathrm{CO}_{2}$-rebreathing technique to estimate pulmonary blood flow, ie, cardiac output. Ohlsson et al (23) compared this technique with the direct Fick method at rest. In the determination of stroke volume there was no significant difference between the two methods 
$(\mathrm{r}=0.90)$, but cardiac output was, on the average, 22 $\%$ higher with the $\mathrm{CO}_{2}$ method because of increased heart rate. We observed that under neutral conditions the hyperventilation needed in the rebreathing procedure increased heart rate by $5-10$ beats $\cdot \mathrm{min}^{-1}$, and probably cardiac output also increased, but in the heat at a higher heart rate the increase was negligible. Thus, in our tests, possible increases in cardiac output in the heat, relative to that in the thermoneutral environment, may have been underestimated. In addition changes of about $0.8 \mathrm{I} \cdot \mathrm{min}^{-1}$ or less (coefficient of variation $7.2 \%$ ) were probably undetectable. We feel, however, that using the averaged cardiac output values and accepting only $\mathrm{CO}_{2}$ curves with a steady exponential rise $(r>0.90)$ considerably reduced the inherent variation caused by the methodology.

In the present study, during prolonged treadmill work requiring $30 \% \mathrm{VO}_{2} \max$, the heart rate was significantly higher in the warm humid and hot dry environments than under the thermoneutral conditions, but, because of the marked reduction in stroke volume, the average cardiac output was not different in the three different environments. The mechanism behind the reduced stroke volume in the heat seems to be related to the increased level of skin blood flow (30), which, together with the reduction in the tone of distensible cutaneous veins (35), increases the pressure and blood volume of the veins. Because $70 \%$ of the blood volume is below heart level in humans and most of it is in the veins, the venous pooling of blood under heat stress reduces cardiac filling, central blood volume, and stroke volume (30). In an upright walking man the muscle pump empties the veins during each contraction, but the arterial inflow is so high that the average venous pressure and volume are increased (10). Dehydration also reduces venous return to the heart by lowering circulating blood volume (19).

In spite of the unchanged mean cardiac output in the heat, there was substantial variation in the individual cardiac output responses (figure 3). A significant part of this variation was probably caused by the aforementioned methodological limitations and by day-to-day biological variation. In addition our subjects were voluntarily dehydrated to different degrees (from 0.1 to $2.9 \%$ ), and this difference may have augmented the variation, especially with respect to the lowered cardiac output values (19). On the other hand, the increases in cardiac output were significantly related to increases in skin blood flow, as estimated by the thermal conductance. Similarly, a significant correlation $(0.74)$ between increases in cardiac output and skin temperature was found during light exercise in water-perfused suits, in which the skin temperature was maintained at different levels (30). Thus at lower work loads higher thermal stress, as indicated by skin temperature or skin blood flow, may be coupled with elevated cardiac output, despite reduced stroke volume. However, in our study, the cardiac output rose over the control value in only one of the nine tests with steady-state responses (figure 4). In six tests it remained unchanged, and in two it decreased slightly. High cutaneous blood flows probably cannot be maintained for long periods of time because of the negative effects on central circulation.

During the prolonged walking tests in the warm humid and hot dry environments the average peripheral systolic blood pressure was significantly lower than in the thermoneutral environment, but after the second bout of exercise it remained stable. Three of the heat stress tests were terminated due to exhaustion of the subjects, whose systolic blood pressures, however, did not show any significant lowering. This result is in agreement with the finding of a relatively constant mean aortic blood pressure during exhaustive work in dry heat (28). Naturally, in the cases of heat syncope, a drastic fall in mean aortic blood pressure must have occurred. In the three exhausted subjects the exhaustion was characterized by a high heart rate $(>150$ beats. $\min ^{-1}$ ), a rectal temperature of $\approx 38.4^{\circ} \mathrm{C}$, and a steadily decreasing stroke volume. In two of the subjects cardiac output was elevated over the control values. The relatively low rectal temperatures imply that, during acute exercise-heat stress, circulatory instability rather than hyperthermia may be a factor limiting prolonged work performance.

\section{Comparison of the responses of the trained and untrained men}

In 1965 Piwonka et al (25) began the discussion on whether physical training can substitute heat acclimation. At present, the experimental evidence indicates that endurance-type physical training enhances sweating $(8,9,20)$ and may increase heat tolerance by 50 $\%$ of that achieved by heat acclimation (1). Frequent rises in internal body temperature during training sessions seem to be the prerequisite for these changes ( 1 , 8).

A strict comparison of the trained and untrained groups is not justified in our study because the trained men were exposed to extra postural stress during the blood pressure measurement in a standing position. (See the Subjects and Methods section.) In the thermoneutral environment the trained subjects, because of their higher absolute work loads, had a higher mean cardiac output, a higher stroke volume and a higher oxygen consumption than the untrained men, but, due to the higher evaporation rates and thermal conductances of the trained men, the heart rates and rectal temperatures of the two groups were similar. However, in the light of earlier studies $(1,8,9)$, it was somewhat surprising to note that, in the heat, the heart rate and rectal temperature responses did not differ between the two groups, and actually they were slightly higher in the trained men. The physically trained men had significantly higher sweat rates in the heat, but the relative amount of evaporation was significantly lower, especially in the warm humid environment (reduced 
sweating efficiency). Actually, in the warm humid environment, the predicted required skin wetness level (13) for the trained men exceeded unity (1.13). Therefore the evaporation rate required to maintain heat balance would be very difficult to achieve even by acclimated persons. Because the study was performed in the wintertime and most of the physically trained subjects exercised outdoors (skiing, jogging), these subjects may have not experienced the same elevations in internal body temperature as in other studies $(1,8,9)$. During long-distance skiing requiring $75 \% \mathrm{~V}_{2}$ max, the mean skin temperature of one man varied between 21.0 and $24.0^{\circ} \mathrm{C}$ and the rectal temperature between 37.5 and $38.0^{\circ} \mathrm{C}(31)$.

It is important to note, however, that in our study the advantage of physical training in respect to work performance was nearly maintained in the warm humid and hot dry environments, because the absolute amount of physical work done by the trained men was higher. In other words, in hot workplaces with fixed work tasks, the physiological strain will be lower in the more physically fit person.

In summary, a warm humid and a hot dry environment with nearly equal WBGT values produced marked circulatory and thermal strain in unacclimated men performing prolonged, light physical work while wearing work overalls. On the basis of heart rate and rectal temperature no statistically significant difference in physiological strain was found between the warm humid and hot dry environments or between the physically trained and untrained subjects. In the heat, heart rate was significantly higher than under thermoneutral conditions, but because of reduced stroke volumes the mean cardiac output was not different in the three environments. At the individual level, the increases in cardiac output were related to increases in skin blood flow, but not to an attainment of a physiological steady state during prolonged work. The present results indicate that during acute heat exposure impaired work performance is mainly related to circulatory instability caused by peripheral circulation that is increased for heat dissipation.

\section{Practical conclusions}

The marked extra circulatory and thermal strain observed in the heat stress tests indicates that continuous work at the WBGT value of about $28^{\circ} \mathrm{C}$ should be avoided and rest pauses in cooler environments should be incorporated into the workshift. New workers in hot workplaces are at increased risk for heat syncope, and they should be warned about stationary work positions. Physically trained persons seem to be as affected by acute heat exposure as untrained persons if the relative aerobic strain is the same. Heart rate monitoring may be a useful method for assessing workers' physiological strain in a hot environment because, during prolonged work, it was associated with reduced stroke volume rather than with increased cardiac output.

\section{Acknowledgments}

The authors express their appreciation to $\mathrm{Mr} \mathrm{M}$ Ahonen for his untiring help with the laboratory techniques throughout the course of the study. Ms L Roisko and Ms S Reponen are thanked for their secreterial assistance. $\mathrm{Mr} \mathrm{H}$ Ollila is thanked for his help in analyzing the $\mathrm{CO}_{2}$-rebreathing curves.

Juhani Smolander was supported by a personal grant from the Finnish Ministry of Education.

\section{References}

1. Avellini BA, Shapiro Y, Fortney SM, Wenger CB, Pandolf KB. Effects on heat tolerance on physical training in water and on land. J Appl Physiol Respir Environ Exercise Physiol 53 (1982): 5, 1291-1298.

2. Bean WB, Eichna LW. Performance in relation to environmental temperature: Reactions of normal young men to simulated desert environment. Fed Proc 2 (1943) $144-158$.

3. Brouha L. Physiologic effect of work on the heart. In: Warshaw LF, ed. The heart in industry. Hoeber, New York, NY 1960, pp 47-104.

4. Damato AN, Lau SH, Stein E, Haft JI, Kosowsky B, Cohen SI. Cardiovascular response to acute thermal stress (hot dry environment) in unacclimatized normal subjects. Am Heart J 76 (1968) $769-774$.

5. Dill DB, Edwards HT, Bauer PS, Levenson EJ. Physical performance in relation to external temperature. Arbeitsphysiologie 4 (1931) 508-518.

6. Farhi LE, Nesarajah MS, Olszowka AJ, Metildi LA, Ellis AK. Cardiac output determination by simple onestep rebreathing technique. Respir Physiol 28 (1976) $141-159$.

7. Futatsuka M, Pyykkö I, Färkkilä M, Korhonen O, Starck J. Blood pressure, flow, and peripheral resistance of digital arteries in vibration syndrome. $\mathrm{Br} \mathrm{J}$ Ind Med 40 (1983) $434-441$.

8. Gisolfi CV. Work-heat tolerance derived from interval training. J Appl Physiol 35 (1973) 349-354.

9. Henane R, Flandrois R, Charbonnier JP. Increase in sweating sensitivity by endurance conditioning in man. J Appl Physiol 43 (1977) 822-828.

10. Henry JP, Gauer OH. The influence of temperature upon venous pressure in the foot. J Clin Invest 29 (1950) $855-861$.

11. Ilmarinen R. Einflüsse verschiedener Bekleidung auf einige physiologische Grössen des Menschen bei Körperarbeit in unterschiedlich erhöhter Umgebungstemperatur und Luftfeuchtigkeit. Deutsche Sporthochschule, Köln 1978. (Doctoral dissertation).

12. International Organization for Standardization. Hot environments - Estimation of heat stress on working man based on the WBGT index (Wet Bulb Globe Temperature). Geneva 1982. (ISO 7243-1982).

13. International Organization for Standardization. Hot environments - Analytical determination of thermal stress. Geneva 1984. (ISO/DIS 7933).

14. Johnson JM, Rowell LB. Forearm skin and muscle vascular responses to prolonged leg exercise in man. J Appl Physiol 39 (1975) 920-924.

15. Leithead CS, Lind AR. Heat stress and heat disorders. Davis, Philadelphia, PA 1964.

16. Louhevaara V, Tuomi T, Smolander J, Korhonen O, Tossavainen A, Jaakkola J. Cardiorespiratory strain in jobs that require respiratory protection. Int Arch Occup Environ Health 55 (1985) 195-206.

17. Miyamura $\mathrm{M}$, Honda $\mathrm{Y} . \mathrm{CO}_{2}$ dissociation curves of oxygenated whole blood obtained at rest and in exercise. Eur J Appl Physiol Occup Physiol 39 (1978) 37 - 45. 
18. Nadel ER, Cafarelli E, Roberts MF, Wenger CB. Circulatory regulation during exercise in different ambient temperatures. J Appl Physiol 46 (1979) 430-437.

19. Nadel ER, Fortney SM, Wenger CB. Effect of hydration state on circulatory and thermal regulations. J Appl Physiol 49 (1980) 715-721.

20. Nadel ER, Pandolf KB, Roberts MF, Stolwijk JAJ. Mechanisms of thermal acclimation to exercise and heat. J Appl Physiol 37 (1974) 515-520.

21. Nielsen B, Nielsen SL, Petersen FB. Thermoregulation during positive and negative work at different environmental temperatures. Acta Physiol Scand 85 (1972) 249-257.

22. Niemelä R, Ilmarinen R. Lämpöolosuhdemittaukset vuosina 1969-79 [Measurements of the thermal climates at worksites between 1969 and 1979]. Institute of Occupational Health, Helsinki 1983.

23. Ohlsson J, Hlastala MP, Tranesjö J, Wranne B. Noninvasive determination of effective stroke volume: Evaluation of a $\mathrm{CO}_{2}$-rebreathing method in normal subjects and patients. Clin Physiol 3 (1983) 9-18.

24. Oja P, Louhevaara V, Korhonen O. Age and sex as determinants of the relative aerobic strain of nonmotorized mail delivery. Scand J Work Environ Health 3 (1977) $225-233$.

25. Piwonka RW, Robinson S, Gay VL, Manalis RS. Preacclimatization of men to heat by training. J Appl Physiol 20 (1965) 379-383.

26. Root RW. Blood $\mathrm{CO}_{2}$ absorption as function of $\mathrm{CO}_{2}$ pressure. In: Dittmer DS, Grabe RM, ed. Handbook of respiration. Saunders, Philadelphia, PA, and London 1958, p 64.
27. Rowell LB. Human cardiovascular adjustments to exercise and thermal stress. Physiol Rev 54 (1974) 75-159.

28. Rowell LB, Kraning II KK, Kennedy JW, Evans TO. Central circulatory responses to work in dry heat before and after acclimatization. J Appl Physiol 22 (1967) $509-518$.

29. Rowell LB, Marx HJ, Bruce RA, Conn RD, Kusumi F. Reductions in cardiac output, central blood volume, and stroke volume with thermal stress in normal men during exercise. J Clin Invest 45 (1966) $1801-1816$.

30. Rowell LB, Murray JA, Brengelmann GL, Kraning II KK. Human cardiovascular adjustments to rapid changes in skin temperature in exercising man. Circ Res 24 (1969) $711-724$.

31. Smolander J, Louhevaara V, Ahonen M. Clothing, hypothermia, and long-distance skiing. Lancet 2 (1986) $226-227$.

32. Suzuki Y. Human physical performance and cardiocirculatory responses to hot environments during submaximal upright cycling. Ergonomics 23 (1980) $527-542$.

33. Winer BJ. Statistical principles in experimental design. McGraw-Hill, New York, NY. 1971.

34. Wyndham CH, Rogers GG, Senay LC, Mitchell D. Acclimatization in a hot, humid environment: Cardiovascular adjustments. J Appl Physiol 40 (1976) 779 - 785.

35. Zitnik RS, Ambrosioni E, Shepherd JT. Effect of temperature on cutaneous venomotor reflexes in man. $J$ Appl Physiol 31 (1971) 507-512.

Received for publication: 11 June 1986 